\title{
IMPACT OF WORLD TRADE ORGANIZATION (WTO) MEMBERSHIP ON HEALTH LABORATORY SERVICES OF NEPAL
}

Shukla P K

\section{ABSTRACT}

With induction of Nepal into the World Trade Organization (WTO) members group of countries several sectors shall have to be brought upto the internationally accepted standards. Since Health Services have also been included in the 'services' to be covered, the same shall also need attention accordingly . One of the crucial aspects of these is Laboratory services. The author with his experience in India on this aspect elaborates various' angles of details and emphasizes need for action.

\section{Key Words: WTO, Laboratory Accreditation, External Quality Assurance.}

\section{INTRODUCTION}

After 14 years of incubation period now Nepal is formally entered into the World Trade Organization (WTO). No doubt this would produce many beneficial spinoffs, some routers are likely to be affected needing attention, like those in Health sector in a different way.

Like some other developing countries the main concern at present centers naturally around the impact upon agriculture and terms of foreign investment. However, one important aspect is the impact upon some services and experiences of other developing countries may help. Health services have also been included in the sectors involved and laboratory services from an integral part of these.

The core of WTO is to redress imbalances in 'trade and service' amongst its member countries. Indirectly this implies that both these sectors shall have to be brought upto levels acceptable by WTO. Tourism forms an appreciable aspect of Nepal's economy and is basically and intensively 'service' oriented sector. Also, with the increased foreign investment and resultant inflow of foreigners in corporate sector, interaction with Health Services shall have to be closely looked into.

The author has been closely associated with the process of improvement of lab services in India. ${ }^{1-11}$ As the Founder
Organiser of Indian Association of Pathologists and Microbiologists- National External Quality Assurance Programme (IAPM-NEQAP) ${ }^{12}$ since 1989 which now covers some 300 labs all over country, has witnessed the phenomenal changes in lab services scenario after India became WTO member in mid 90's. The author is also member of Committee for National Accreditation Board for Laboratories (NABL) under the Department of Science \& Technology Govt. of India. Various closely studied aspects and the experiences gained could be found useful in Nepal's context because of close similarity in the social and health services structures between the two neighbouring developing countries.

\section{VARIOUS ASPECTS OF THE IMPACT}

Impact of WTO are discussed below as questions and answers:

1. Why should health labs be concerned about WTO?

Uniform 'service' standards desired under WTO naturally include Health Labs. Well established norms are accepted by all developed countries and many developing countries like India and China have already moved in this direction. With increased international presence by trade and investments in Nepal (like proposed 15\% mandatory foreign employees in foreign investment establishments) situations necessitating involvement of Health Labs are unavoidable.

Address for correspondence : $\quad$ Dr. P. K. Shukla

Kathmandu Medical College, Sinamangal, Kathmandu, Nepal

Email: drpkshukla@ hotmail.com 


\section{Flow uniformity would be achieved?}

WTO recognizes standards prescribed by International Standards Oragnistion (ISO) ${ }^{13}$ which is a world wide federation of standardization bodies of more than 100 countries, its guidelines were first published in 1987 and updated from time to time. The aim is to promote development of standardization related activities with a view to facilitate exchange of goods and services and develop cooperation of intellectual scientific technology and economic activities. By becoming member of WTO, a country automatically accepts to enforce these norms in all the aspects prescribed. A natural corollary would be uniformity involving that in the 'services' provided by health labs.

\section{How ISO parameters ensure uniformity?}

Enforcement of ISO has been making steady progress for the last quarter century. At present the norms prescribed by it or are used as national standards in member countries in more and more fields of everyday life. This is being done by making suitable Regional Adaptations conforming to criteria laid down by ISO and acceptable to it. This is done through four ISO standards prescribed.

\section{What are the four ISO standards?}

The four ISO standards are:

i. ISO 9001 - Quality system- model for Quality Assurance (QA) in design development, production, installation and servicing.

ii. ISO 9002 - Quality systems - model for QA in Product installation and servicing

iii. ISO 9003 - Quality systems - model for QA in final inspection and tests.

iv. iSO 9004- Quality management and Quality system elements guidelines.

\section{How lab services are affected by ISO?}

Lab services being a 'service' come under ISO 9001 and 9002. Specifications prescribed under it are very detailed and aimed at attaining very high standards in all aspects of services. The ramification for Health Labs is to ensure that reports from Health labs in a country apply with same degree of relevance in all WTO member countries. In other words 'Reliability and Quality' are to be insured at internationally accepted standards. This is done through Lab Accreditation by ISO or organizations approved/accepted by it.

6. What is Lab Accreditation?

Lab Accreditation is the process of identifying and giving
Certificate of Distinction to labs that fulfil criteria laid down by an independent, competent and authorized organization in one or more fields of lab services.

\section{What is the background of health Lab Accreditation?} USA has been in the fore front of Lab Accreditation .The process in this direction can be traced to early 1960 s'. By mid sixties strong voices were raised by public about reliability of lab services. The US Congress passed the historic Clinical Laboratories Improvement Act (CLIA 1967). The Act mandated the enforcement of reliability and uniformity in lab services (CLIA - 1967) updated to CLIA -- 88. College of American Pathologists (CAP) was approved as an Accreditation Organisalion by the Ultimate Regulatory Authority of the US Govt. in 1995. Tremendous progress has been made since then and, it covered more than 6000 Health Labs in USA and 25 other countries by $2002 .{ }^{14}$

\section{What about Lab Accreditation in countries not covered by CAP?}

In this regard, the importance of ISO assumes great significance . Basically ISO encompasses an extremely wide spectrum of everyday life ranging from industry to food processing and services like banking and hotels. However, parameters applicable to hospitals and services provided therein have been well defined and are available. For more effective implementation some Regional Adaptations like Pan American, European. South Pacific Regional, National Accreditation and Testing Authority (NATA), ${ }^{15}$ Australian and South African adaptations have also been made. Further, ISO also' recognises' (if found suitable ) a local Standardization Body in a particular country like Bureau of Indian Standards (BIS) in India, as complimentary bodies. India has now its own Health Lab Accreditation System accepted on lines of ISO and other international bodies like (NATA). It is National Accreditation Board for Laboratories (NABL) of the Department of' Science \& Technology, Govt. of India. ${ }^{16}$

\section{How does the consumer identify an Accredited Lab?} The labs accredited by CAP,ISO,NABL or any other internationally accepted accrediting body issue a Certificate of Accreditation in the particular branch (s) of health lab service. They are entitled to use the respective logo of accreditation on their report pad or signboards also. Thus, the consumer can easily differentiate an 'accredited' lab from a 'non accredited' one and can understand that accredited has means minimum standards are maintained. 
10. What are the advantages of Lab Accreditation?

The advantages are:

i. Surity that the results from the accredited lab shall be reliable and comparable to any other accredited lab elsewhere in the world. In the present age of fast transport. it means that the reports from it apply with same degree of relevance anywhere.

ii. Status of distinctiveness amongst other labs

iii. Greater faith of the patients and clinicians

iv. Client satisfaction

v. Favourable / linient view in cases under consumer courts for alleged 'negligence'

\section{What if we do not care?}

i. Being in contravention of WTO, the Govt might have to intervene through mandatory licensing system and stop running of sub standard labs (like done in case of blood banks by WHO/Red Cross).

ii. Increased foreign visitors and employees of foreign companies due to trade liberalization would seek services from Accredited labs Italy due to insurance reimbursement angle in their own countries.

iii. If local labs do not raise the desired standards, accredited international diagnostic companies may start opening their branches here.

\section{What is the solution?}

Health Lab Services of Nepal have to be reviewed and upgraded in light of ISO norms. Obviously, due to resource restrictions and other problems, the entire network of laboratories across the country can not be expected to be covered. However, a general improvement in standards would be desirable. As regards Accreditation, some labs in suitable places could be selected and upgraded accordingly. Besides this, labs being run under private sector could play a more active role. Systematic internal Quality Control should be documented and an effective national External Quality Assurance Programme be available under a competent body as pre- requisites for Accreditation. Various other aspects necessary fur Lab Accreditation by ISO be sought to be fulfilled too.

\section{CONCLUSION}

Entry into WTO group of countries brings Nepal to threshold of opportunities as well as challenges in several fields. Health Lab services would form an important aspect affecting a large number of people. These would have to be upgraded through a process of Lab Accreditation by WTO recognized Lab Accreditation Bodies otherwise all the benefits of WTO membership in this important sector would not be reaped. Well documented Internal Quality Control and proven track record through an independent External Quality Assurance system from cornerstones of Lab Accreditation by any international body. However, at present there is much to be desired on these aspects. It is therefore, essential that timely attention be paid to the same to lay solid foundation for better, efficient and internationally acceptable Health Laboratory services in Nepal.

\section{REFERENCES}

1 Shuk a PK Qal i ty Contrd Data Docunentati on in 0 i ni cal Chenistry. My experi ence in Damam, Saud Ned cal J ournal, Ri yach and London 1986- 7-649.

2 Shk a PK Pel evance of Qea ity Contrd to di i ical Service in I ndi a, I nd. J Path \&Mardi ol 1986, 293455.

3 Shukl a PK, Sal askar VH Randeo I N, 'Tal i b VH and Nagal oti nath SJ Resul ts of I APMNati onal Survey on Lab Servi ce Standards and Teachi ng of $\mathrm{O}$ i ni cal and Chenical Pathd ogy and Qher Pel ated Aspects in I nd a: (1989) Ed I nd J Path \& Mcrobi d 1990, 33: .

4 Shukl a P. K I APMNati onal Qual i ty Control Programe in Chenical Pathol ogy, 1990-1991, I nd. J Path \& Mcrobi ol 1994, 38: 129- 36.

5 Shuk a P. K. Constrai nts in Ensuring Standards in Heal th Laboratori es in I nd a, QA News, Ed Sudarshan Kunari, WHO SEARO NewDel hi J une 1998; I-3.

6 Shuk a P1K external Qal i ty Assessnent in I nd a Coveri ng d fferent aspects of' Laboratory Nedi ci ne, QA Neus, Ed Sudarshan Kunari, VHOSEARO New Del hi, April 1999; I :23

7. QA Neus Ed, Sudarshan Kunari , WHO -SEARQ New Del hi, OCt. 1998, l: 4

8 Shk a P. K. I aboratory Servi ce in Inda in Light of Consuner Avareness Ed I nd. J Path \& Mcrdai ol 1992; 35.

9 Shuk a P. K Role of Qal i ty Contrd in Laboratory Mad d ne" Current Trends in Dagnosti c Ai ds" I nternati onal Acadeny of Pathol ogy Ind a Dvisi on, Ed VHTal ib, Pune, 1992; 59-66.

10. Shukl a PK Qual i ty Control in Chenical Pathol ogy, its Background and Techni que of Appl i cati on, I nd. L Path \& Mcrobi ol 1994; 38: 137+ 52.

11. Shuk a PK, Redefi in ing Status of Pathol ogy and Mcrodi ol ogy, Ind. J Path \& Mcrobi d 1998; 41: 377-79.

12. Shukl a PK I APMANEQAP, the ten years growth success I nd an J Pathol Mcrobi d 2000 43(4), 493-506.

13. ISO: ssri ri 38 @ahoo.com

14. CAP WwW cap. org and accred@ap. org

IS NATA : http/ / www nata. asu. au

16 NAB: wwrnabl-i ndia. org

$$
\text { 必必为 }
$$

